\title{
AVALIAÇÃO DE METAIS PESADOS NOS RECURSOS HÍDRICOS DO MUNICÍPIO DE BOQUIRA, NO SEMIÁRIDO BAIANO - BRASIL
}

\author{
EVALUATION OF HEAVY METALS IN WATER RESOURCES OF THE MUNICIPALITY OF \\ BOQUIRA, IN SEMI-ARID OF BAHIA - BRAZIL
}

\section{Rafael Ribeiro DALTRO, José Ângelo Sebastião Araújo dos ANJOS, Maria da Conceição RABELO GOMES}

Universidade Federal da Bahia, Instituto de Geociências. Departamento de Geologia. Avenida Adhemar de Barros, s/n. Ondina, Salvador, - BA, Bahia, Brasil. E-mails: rfdaltro@gmail.com; jose.anjos@ufba.br; conceicaorabelo@yahoo.com.br

\author{
Introdução \\ Caracterização da Área \\ Material e Métodos \\ Resultados e Discussão \\ Considerações finais \\ Referências
}

\begin{abstract}
RESUMO - O município de Boquira, localizado na porção centro sul do estado da Bahia, está situado em um ambiente geológico com importante background natural para $\mathrm{Pb}$ e $\mathrm{Zn}$, onde hospedou entre os anos de 1960 e 1992 a maior mina de $\mathrm{Pb}$ e $\mathrm{Zn}$ do Brasil. Diante disso, buscou-se avaliar a qualidade dos recursos hídricos utilizados para abastecimento humano no município, frente a uma possível contaminação natural e/ou antrópica por metais, e a influência dos passivos ambientais deixados no município após o súbito abandono da mineração. Para tanto, realizou-se campanhas de campo e amostragem de alíquotas de água objetivando a realização de análises químicas laboratoriais para monitoramento e comparação com outros autores. Concluiu-se que existe influência do background natural das rochas do município de Boquira nos recursos hídricos utilizados pela população, conferido valores acima do Valor Máximo Permitido para consumo humano para metais como Ca, $\mathrm{Fe}, \mathrm{Mg}$ e $\mathrm{Na}$. Apesar das maiores concentrações para metais como $\mathrm{Pb}, \mathrm{Zn}$ e Cd estarem situadas nas águas das galerias da mina subterrânea e bacia de rejeito, não foi encontrado elevados teores desses metais nos recursos hídricos analisados.
\end{abstract}

Palavras-chave: Impactos ambientais; Água; Nordeste.

\begin{abstract}
The municipality of Boquira, located in the south central portion of the state of Bahia, is situated in a geological environment with important natural background for $\mathrm{Pb}$ and $\mathrm{Zn}$, where it hosted between the years of 1960 and 1992 the largest mine of $\mathrm{Pb}$ and $\mathrm{Zn}$ of Brazil. The aim was to evaluate the quality of the water resources used for human consumption in the municipality, against possible natural and/or anthropic contamination by metals, and the influence of the environmental liabilities left in the municipality after the sudden abandonment of the mining. For this purpose, field campaigns and water aliquot sampling were carried out with the objective of performing laboratory chemical analysis for monitoring and comparison with other authors. It was concluded that there is influence of the natural background of the rocks of the municipality of Boquira on the water resources used by the population, given values above the Maximum Allowable Value for human consumption for metals such as $\mathrm{Ca}, \mathrm{Mg}$, and $\mathrm{Na}$. Although the highest concentrations for metals such as $\mathrm{Pb}, \mathrm{Zn}$ and $\mathrm{Cd}$ were in the waters of the underground tailings and mine galleries, high levels of these metals were not found in the analyzed water resources.
\end{abstract}

Keywords: Environmental impacts; Water; Northeast.

\section{INTRODUÇÃO}

O município de Boquira está parcialmente situado no contexto geológico da Unidade Boquira, estudada por diversos autores (Espourteille \& Fleischer, 1980; Rocha, 1985; Arcanjo et al., 2000; Garcia, 2011) devido à presença de importantes mineralizações de chumbo, conferindo importante background natural para metais como chumbo, zinco, ferro, dentre outros.

Associado a este fato, o município hospedou a partir da década de 1960 a maior mina de $\mathrm{Pb}-\mathrm{Zn}$ do Brasil (Cornejo \& Bartorelli, 2010), operando por mais de 30 anos, até ser subitamente abandonada, deixando expressivo passivo ambiental sob forma de material particulado composto por metais tóxicos como chumbo, zinco, prata, bário, cobre, cromo, níquel, arsênio e cádmio, depositado na bacia de rejeito e nas galerias da mina subterrânea.

Os passivos da mineração no município, tais como a disposição de resíduos no entorno da área urbana e nas galerias das minas subterrâneas podem significar importantes fontes de contaminação dos recursos hídricos utilizados no município.

Logo, a pesquisa tem como objetivo, avaliar a qualidade dos recursos hídricos utilizados para abastecimento humano no município de Boquira, frente à uma possível contaminação natural e/ou antrópica por metais, assim como a influência dos passivos ambientais deixados pela mineração no município. 


\section{CARACTERIZAÇÃO DA ÁREA}

A área de estudo está localizada no município de Boquira, situado na porção centro sul do estado da Bahia. Apresenta área total de unidade territorial de 1.426,233 km² (IBGE, 2015), mantendo limites territoriais com os municípios de Macaúbas, Ibipitanga, Ibitiara, Oliveira dos Brejinhos e Paratinga.

As principais unidades aflorantes na área de estudo correspondem às rochas do Complexo Paramirim, Complexo Boquira (Unidade Botuporã, Unidade Cristais e Unidade Boquira), Granito de Boquira, Supergrupo Espinhaço (indiviso) e depósitos coluvionares e aluvionares (Arcanjo et al., 2000).

A área é caracterizada como zona de clima semiárido, quente e seco, com temperaturas médias anuais iguais ou superiores a $18^{\circ} \mathrm{C}$. As maiores precipitações concentram-se entre os meses de novembro e março, com precipitação média de $122 \mathrm{~mm}$, enquanto a época de estiagem concentra-se no período de maio a setembro com precipitação média de $6 \mathrm{~mm}$ (IBGE, 2015).

A ocorrência da água subterrânea armazenada nos aquíferos da região semiárida se dá predominantemente em zonas subverticais estreitas, associadas aos intensos conjuntos de falhamento, com cerca de 10 a 15 metros de profundidade, sempre abaixo de um manto incipiente de rocha alterada (Lima, 2003). Segundo Giampa \& Gonçales (2013), a água subterrânea armazenada nos aquíferos é controlada por condições específicas que integram fatores hidro climáticos e aspectos geológicos, influenciando diretamente na qualidade das águas.

\section{MATERIAL E MÉTODOS}

O planejamento para a realização deste trabalho foi dividido em duas campanhas (Julho/2016 e Setembro/2016) descritas a seguir.

Campanha I (Julho/2016): Foram selecionados em campo, 14 pontos para análise, sendo destes um total de 08 poços tubulares, 04 nascentes e 02 cisternas (Figura 1) baseados nos seguintes critérios: proximidade do ponto com a bacia de rejeito; entradas das galerias da mina subterrânea e cava da mina superficial; utilização da água para abastecimento humano, unidade litoestratigráfica e possibilidade de cruzamento de dados com análises químicas realizadas por Cunha et al. (2016) em julho de 2013 (poços tubulares, nascentes, cisternas e rampa da mina).

Campanha II (Setembro/2016): realizou-se para cada ponto predefinido a mensuração in loco dos parâmetros físico-químicos: Temperatura; Potencial Hidrogeniônico (pH); Condutividade Elétrica (CE); Turbidez; Oxigênio Dissolvido (OD); Sólidos Totais Dissolvidos (STD) e Salinidade, utilizando uma sonda multiparâmetros modelo Horiba U-52G, previamente calibrada e posteriormente realizada a amostragem de pontos d'águas (poços tubulares, nascentes e cisternas) para análise de metais.

Foram acondicionadas em recipientes de polietileno de $250 \mathrm{ml}$, previamente preparadas com $\mathrm{HNO}_{3}$ e após amostradas, acondicionadas em ambiente refrigerado $\left(0\right.$ a $\left.6{ }^{\circ} \mathrm{C}\right)$ pelo período máximo de 04 dias, enquanto as alíquotas para análise de nitrato foram armazenadas em recipientes de polietileno de $500 \mathrm{~mL}$, sem acidificação e mantidas refrigeradas por até 72 horas antes das análises.

As análises das alíquotas amostradas na campanha II, realizada em setembro/2016, para os cátions $\mathrm{As}^{3+}, \mathrm{Ca}^{2+}, \mathrm{Cd}^{2+}, \mathrm{Fe}^{2+}, \mathrm{Mg}^{2+}, \mathrm{Na}^{+}$, $\mathrm{Pb}^{2+}, \mathrm{Zn}^{3+}$ foram realizadas no Laboratório Merieux NutriSciences - Bioagri Ambiental LTDA, acreditado pelo INMETRO (CRL 0172), segundo os requisitos estabelecidos na norma ABNT NBR ISO/IEC 17025:2005 utilizando o método ICP-OES9, com duplicatas. As análises para o ânion nitrato $\mathrm{NO}_{3}^{-}$foram realizadas no Laboratório de Plasma do IGEO/UFBA, utilizando o método de espectrofotometria de absorção molecular a partir do equipamento Hitachi.

Após os resultados das análises químicas e físico-químicas, foram utilizadas diretrizes para determinar a qualidade das águas nos pontos analisados. Para tal, utilizou-se prioritariamente a Portaria MS 2914/2011 e a Resolução CONAMA 396/2008 por serem as normativas mais recentes em uso na legislação brasileira. Para os demais elementos que não apresentam parâmetros de Valor Máximo Permitido (VMP) nas portarias supracitadas, utilizou-se fontes como a Resolução CONAMA 357/2005 e WHO (2011). 


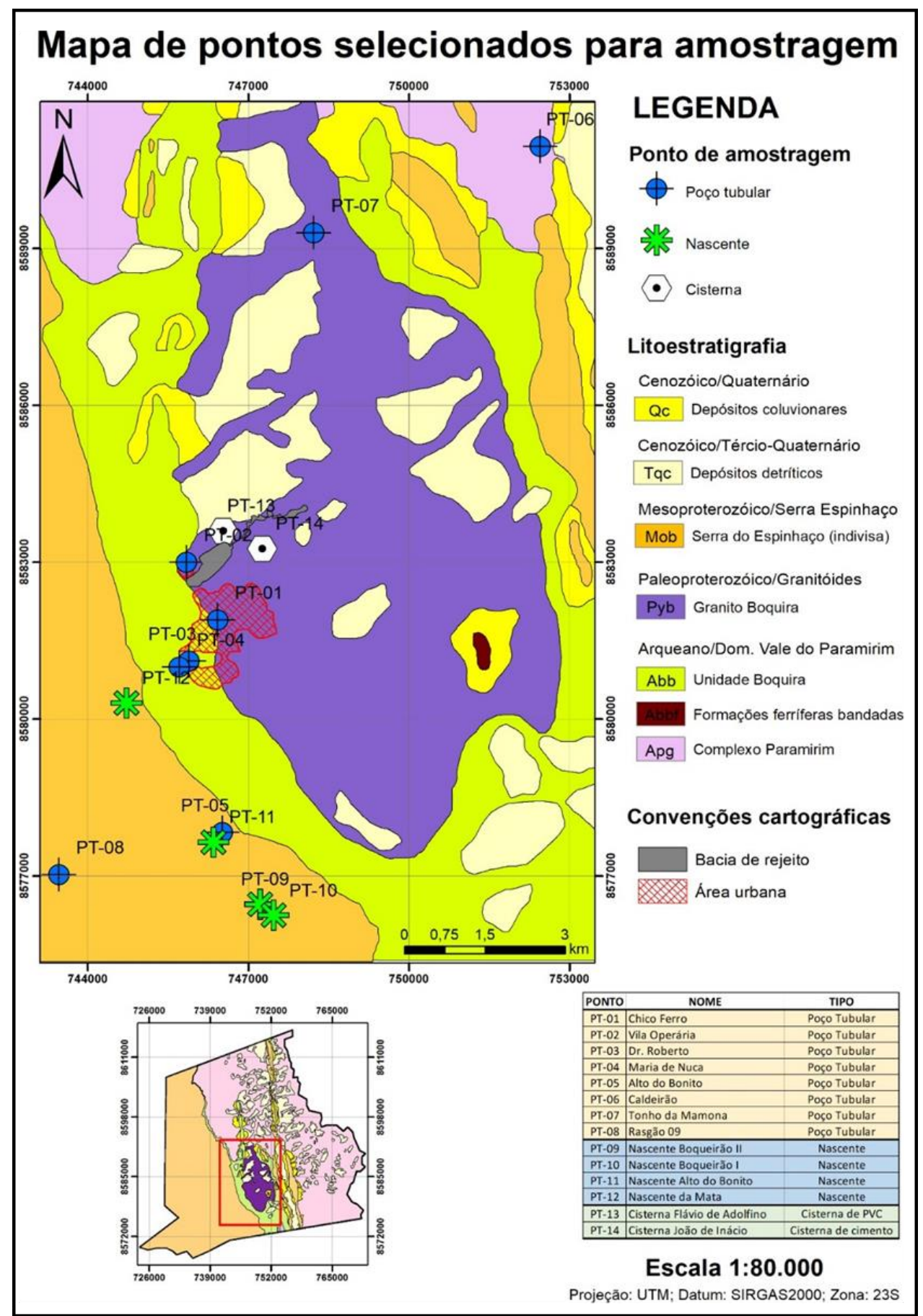

Figura 1 - Localização das unidades geológicas, bacia de rejeito e dos pontos selecionados para amostragem (Julho/2016) (Adaptado de Arcanjo et al., 2000).

\section{RESULTADOS E DISCUSSÃO}

Nas amostras analisadas por Cunha et al. (2016) na campanha de julho/2013, os valores de $\mathrm{pH}$ variaram entre 4,03 e 7,26, enquanto na campanha II realizada em setembro/2016 os valores oscilaram entre 4,4 e 8,39 (Figura 2). Apesar de ambas campanhas de amostragem (campanha II e Cunha et al. (2016)) haverem sido realizadas nos meses de estiagem (julho/2013 e setembro/2016, respectivamente), a divergência nos valores encontrados dever-se ao fato de períodos de estiagem mais prolongados associados à ausência de chuvas em anos anteriores.

A condutividade elétrica ocorre pela propriedade que os sais dissolvidos na água têm de se transformarem em eletrólitos capazes de conduzir corrente elétrica, sendo então um indicador da quantidade de sais existentes na solução. Segundo WHO (2011), a condutividade elétrica depende de variáveis como a concentração iônica e da temperatura, sendo possível relacionar o aumento da temperatura e 


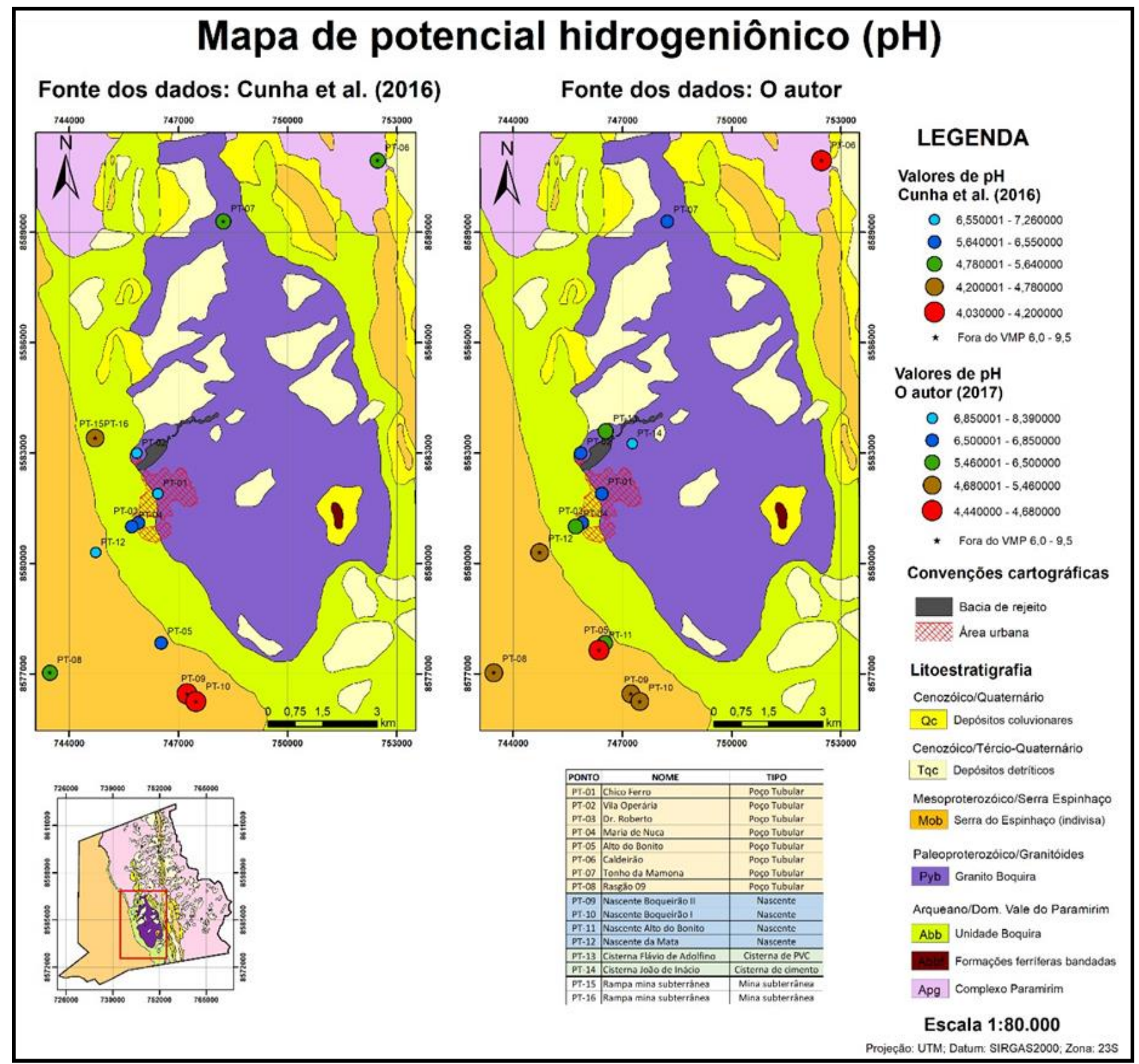

Figura 2 - Potencial hidrogeniônico $(\mathrm{pH})$ com base nos valores obtidos por Cunha et al. (2016) (mapa à esquerda) e campanha II (mapa à direita) (Adaptado de Arcanjo et al., 2000; Cunha et al., 2016; Daltro, 2016).

Apesar de não causar danos imediatos aos seres humanos, a condutividade elétrica pode ser um importante indicativo de contaminação em meios aquáticos. A condutividade elétrica associada com a elevada presença de íons na água pode causar danos às culturas irrigadas.

Como não consta nas legislações brasileiras e internacional parâmetros de VMP para condutividade elétrica, neste trabalho optou-se por utilizar o parâmetro indicado por alguns autores, cujo o valor é de $750 \mu \mathrm{S} / \mathrm{cm}$ (Logan, 1965; Mendes \& Oliveira, 2004), valor limite para que o meio seja considerado salino e impróprio para o consumo humano. Assim, os pontos PT-01 $(1840 \mu \mathrm{S} / \mathrm{cm}-2013$ e $2010 \mu \mathrm{S} / \mathrm{cm}$
- 2016), PT-02 (1952 $\mu \mathrm{S} / \mathrm{cm}$ - 2013 e $1910 \mu \mathrm{S} / \mathrm{cm}$ - 2016), PT-03 (1335 $\mu \mathrm{S} / \mathrm{cm}-2013$ e $1670 \mu \mathrm{S} / \mathrm{cm}$ - 2016), PT-07 (2399 $\mu \mathrm{S} / \mathrm{cm}-2013$ e $2760 \mu \mathrm{S} / \mathrm{cm}$ - 2016), PT-08 (1357 $\mu \mathrm{S} / \mathrm{cm}$ - 2013 e $17 \mu \mathrm{S} / \mathrm{cm}$ 2016), PT-15 (3861 $\mu \mathrm{S} / \mathrm{cm}$ - 2013) e PT-16 (3861 $\mu \mathrm{S} / \mathrm{cm})$ apresentaram valores acima do VMP.

A turbidez é um parâmetro físico utilizado para caracterizar a qualidade da água através da medição óptica da luz dispersa, que por sua vez é produto da interação entre a luz incidente e material em suspensão em um meio líquido, podendo ser o material em suspensão matéria orgânica, partículas inorgânicas, silte, argila e areia, etc. Durante a campanha II realizada em setembro/2016 realizou-se a análise de turbidez 
em 14 pontos, sendo os valores encontrados situados na faixa entre 0,1 uT e 19,7 uT e constando 3 pontos com valores acima do VMP: PT-08 (19,7 uT), PT-09 (19,7 uT) e PT-11 (7,60 uT). De acordo com a Portaria MS n ${ }^{\circ} 2914 / 2011$ o valor máximo permitido para turbidez é de 5 uT.

Os valores de STD encontrados durante amostragem dos 14 pontos da campanha II (Figura 3), realizada em setembro/2016 variaram entre $1 \mathrm{mg} / \mathrm{L}$ e $1770 \mathrm{mg} / \mathrm{L}$, sendo que dos 14 pontos amostrados, 4 apresentaram valores superiores ao VMP: PT-01 (1290 mg/L), PT-02 (1220 mg/L), PT-03 (1070 mg/L) e PT- 07 (1770 $\mathrm{mg} / \mathrm{L})$. De acordo com a Resolução CONAMA $n^{\circ} 396 / 2008$ e a Portaria MS n 2914/2011, o valor máximo permitido para STD é de 1000 $\mathrm{mg} / \mathrm{L}$. Sólidos Totais Dissolvidos (STD) é o parâmetro de avaliação de qualidade das águas cujo objetivo é determinar em solução o volume de substâncias orgânicas e inorgânicas em formas moleculares ou iônicas.

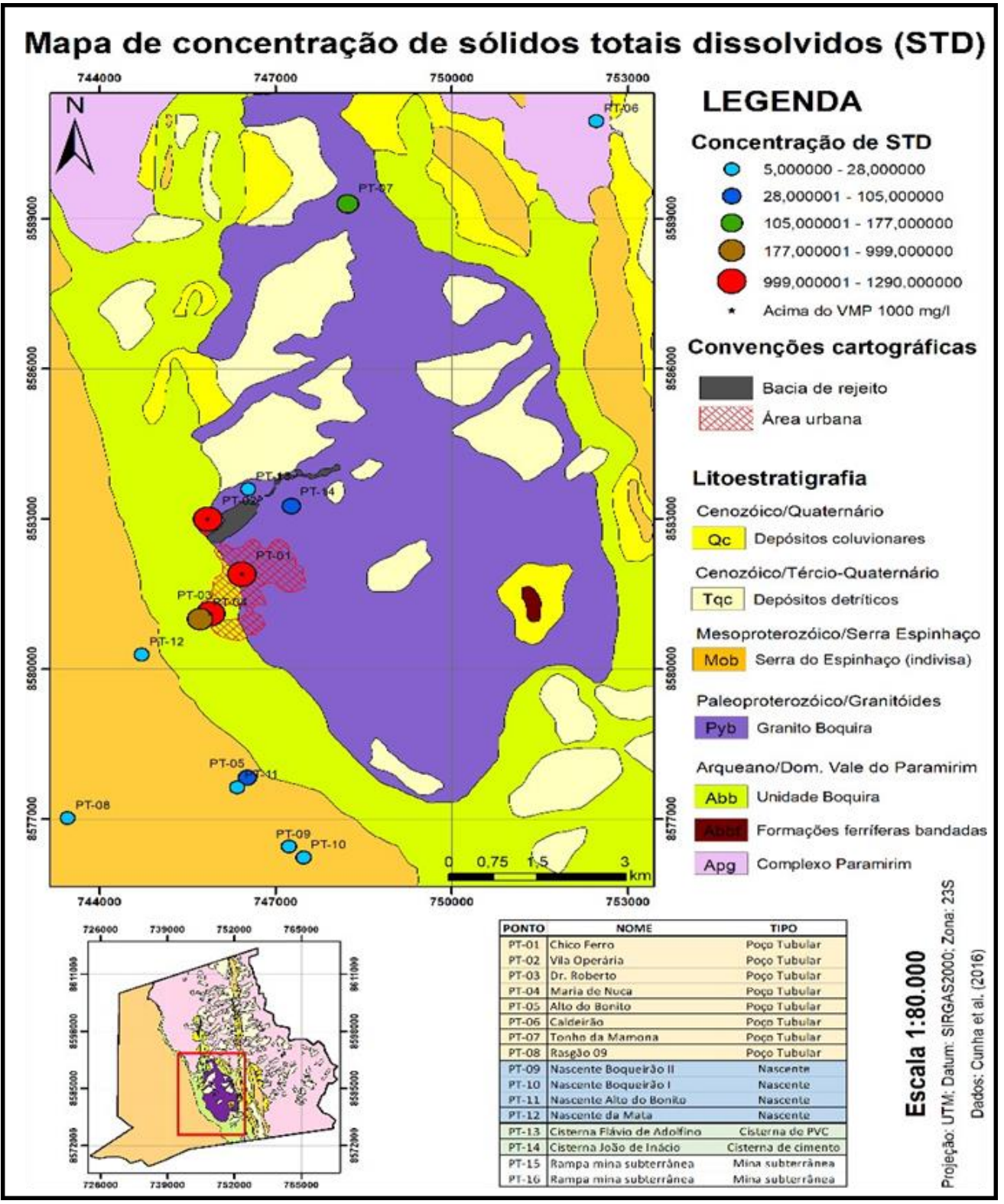

Figura 3 - Concentração de sólidos totais dissolvidos (STD) com base nos valores obtidos na campanha II (Adaptado de Arcanjo et al., 2000).

A ocorrência de chumbo no ambiente se dá predominantemente oriunda de fontes antrópicas como atividades industriais e agrícolas. Para Lima (2010), a origem natural do chumbo é decorrente da interação com minerais como a galera $(\mathrm{PbS})$, cerussita $\left(\mathrm{PbCO}_{3}\right)$ e piromorfita
$\left(\mathrm{Pb}_{5}\left(\mathrm{PO}_{4}\right)_{3} \mathrm{Cl}\right)$, sendo pouco solúvel em meios aquosos com pH > 5,4 (Paoliello \& Capitani, 2003) e insolúvel em ambientes com pH básico (Businelli et al., 2009).

De acordo com a Resolução CONAMA ${ }^{\circ}$ 396/2008 e a Portaria MS n 2914/2011, o valor 
máximo permitido de chumbo na água para consumo humano é $0,01 \mathrm{mg} / \mathrm{L}$. As análises para chumbo das amostras de água de nascente, água subterrânea e de cisterna (PT-01 até PT-14) coletadas na campanha II de amostragem de setembro/2016 apresentaram valores inferiores ao limite de quantificação de $<0,01 \mathrm{mg} / \mathrm{L}$ (Figura 4). Os resultados obtidos nas análises de julho/2013 por Cunha et al. (2016) apontam que as alíquotas analisadas para água superficial e subterrânea apresentam valores abaixo do limite de quantificação, porém os valores encontrados para os pontos PT-15 e PT-16 (rampa da mina subterrânea), apresentaram valores 0,693 e 0,689 $\mathrm{mg} / \mathrm{L}$ respectivamente (Figura 4 ), excedendo o VMP em 69 vezes.

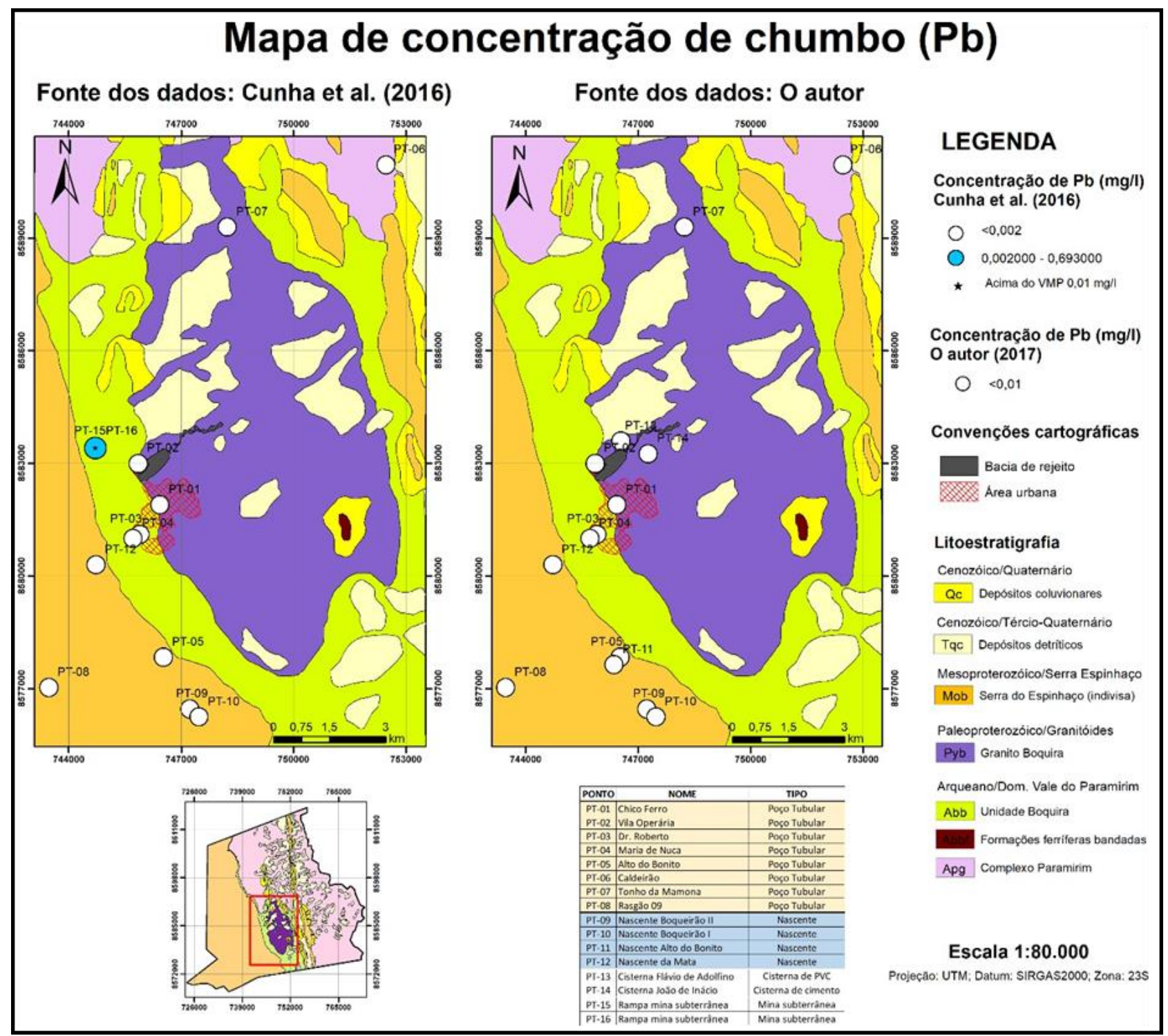

Figura 4 - Concentração de chumbo $(\mathrm{Pb})$ nos pontos amostrados por Cunha et al. (2016) e Daltro (2016). (Adaptado de Arcanjo et al., 2000; Cunha et al., 2016).

Estes índices elevados podem ser explicados devido à grande quantidade de material oriundo da bacia de rejeito depositado nas galerias da mina subterrânea durante $o$ período de funcionamento e após o abandono da mineração, sendo este material composto por chumbo, zinco, arsênio, bário, cádmio, cromo, cobre e níquel (Cunha et al., 2016).

Para Bertolino et al. (2014), o chumbo presente na bacia de rejeito está associado aos minerais como galena $(\mathrm{PbS})$, cerussita $\left(\mathrm{PbCO}_{3}\right) \mathrm{e}$ anglesita $\left(\mathrm{PbSO}_{4}\right)$, na forma de grãos livres ou associados a outros minerais que podem liberar chumbo para o ambiente se expostos a condições intempéricas favoráveis. As concentrações de zinco obtidas nas amostras analisadas em setembro/2016 para água subterrânea, nascente e de cisterna variam de $<0,01$ a $0,149 \mathrm{mg} / \mathrm{L}$ (Figura 5), estando, portanto, todos os pontos analisados com resultados abaixo do valor máximo permitido para consumo humano, que é de 5 mg/L (Resolução CONAMA n ${ }^{\circ}$ 396/2008 e 
Portaria MS n² 2914/2011).

Para as análises realizadas em julho/2013 por Cunha et al. (2016), os resultados variam entre $<0,01$ e $124 \mathrm{mg} / \mathrm{L}$. Os valores para os pontos de água de nascente e água subterrânea apresentaram resultados inferiores ao valor máximo permitido (VMP), porém nos pontos $\mathrm{PT}$ 15 e PT-16 (rampa da mina subterrânea), os valores encontrados excederam o VMP em 24 vezes, conforme observado ainda na figura 5 . Estes valores elevados, assim como os valores para $\mathrm{Pb}$, se devem possivelmente ao material oriundo da bacia de rejeito depositado nas galerias da mina subterrânea.

As concentrações de cádmio (Figura 6) referentes às análises realizadas para a campanha II (setembro/2016) apresentaram valores inferiores ao limite de quantificação para os pontos PT-01 a PT-14, estando, portanto, abaixo do valor máximo permitido para consumo humano de $0,005 \mathrm{mg} / \mathrm{L}$, de acordo com a Resolução CONAMA $\mathrm{n}^{\circ}$ 396/2008 e a Portaria MS n ${ }^{\circ}$ 2914/2011.

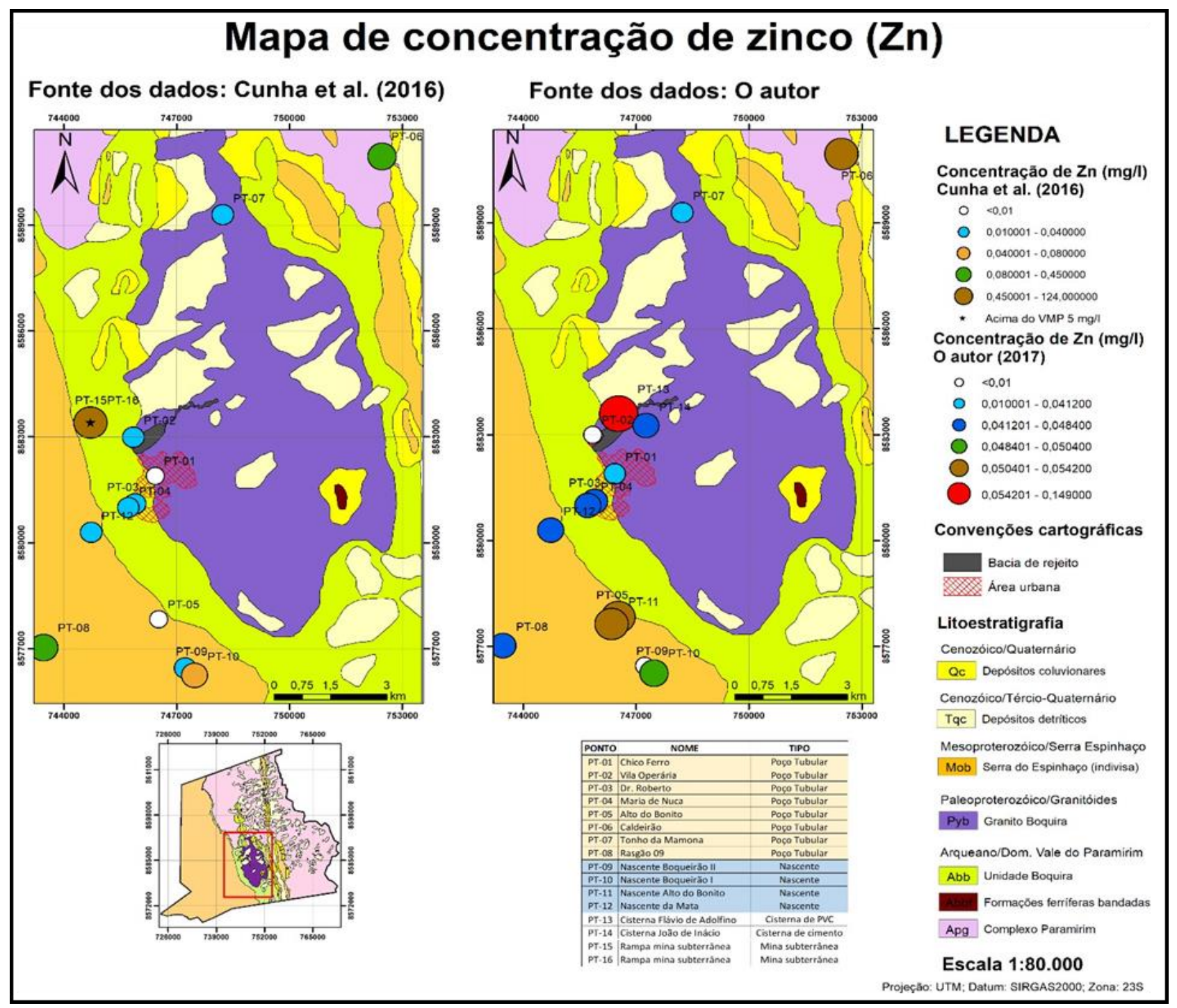

Figura 5 - Concentração de zinco (Zn) com base nos valores obtidos por Cunha et al. (2016) (mapa à esquerda) e campanha II (mapa à direita) (Adaptado de Arcanjo et al., 2000; Cunha et al., 2016).

Os resultados obtidos por Cunha et al. (2016) em campanha realizadas em julho/2013 apontam que os valores para o PT-01 a PT-14 (pontos de águas subterrâneas e nascentes) apresentam valores inferiores ao limite de quantificação, porém os pontos PT- 15 (1,17 mg/L) e PT-16 $(1,24 \mathrm{mg} / \mathrm{L})$ (rampa da mina subterrânea) excedem o VMP de $0,005 \mathrm{mg} / \mathrm{L}$ em 240 vezes.

Segundo Cunha et al. (2016), o cádmio, dentre outros metais, compõe o material particulado oriundo da bacia de rejeito que fora depositado nas galerias da mina subterrânea, podendo-se atribuir a este fato os valores elevados nos pontos PT-15 e PT-16. De acordo com WHO (2011), o cádmio antrópico na água tem como fonte o uso indiscriminado de fertilizantes enquanto que Mendes \& Oliveira (2004) cita a ocorrência de cádmio natural associado a minério de chumbo e 
zinco.

Os resultados para a concentração de arsênio nas amostras analisadas apontam valores inferiores ao limite de quantificação de $<0,01$ $\mathrm{mg} / \mathrm{L}$ para os resultados obtidos durante a campanha II (setembro/2016) e por Cunha et al. (2016) em julho/2013.

Para Santos (2008) a origem do cálcio nas fontes naturais de água está relacionada à presença de minerais carbonáticos (calcita, aragonita, siderita, cerussita, etc), sendo este o elemento de maior abundância nas águas subterrâneas. Apesar de não haver um consenso com relação aos valores de referência para cálcio em água, de acordo com WHO (2011), o VMP para cálcio é de $75 \mathrm{mg} / \mathrm{L}$, uma vez que não existem estudos de toxidade do cálcio, sendo o maior problema para as águas portadoras de limites maiores do que $75 \mathrm{mg} / \mathrm{L}$, os elevados índices de dureza.

As concentrações de cálcio $(\mathrm{Ca})$ nas amostras analisadas por Cunha et al. (2016) em julho/2013, apontam valores acima do VMP em 8 dos 13 pontos analisados, com resultados entre $0,98 \mathrm{mg} / \mathrm{L}$ e $578 \mathrm{mg} / \mathrm{L}$ para poços tubulares, nascente e rampa da mina subterrânea, sendo para os pontos PT-01 (216 mg/L), PT-02 (277 mg/L) e PT-03 (202 mg/L). A campanha II, realizada em

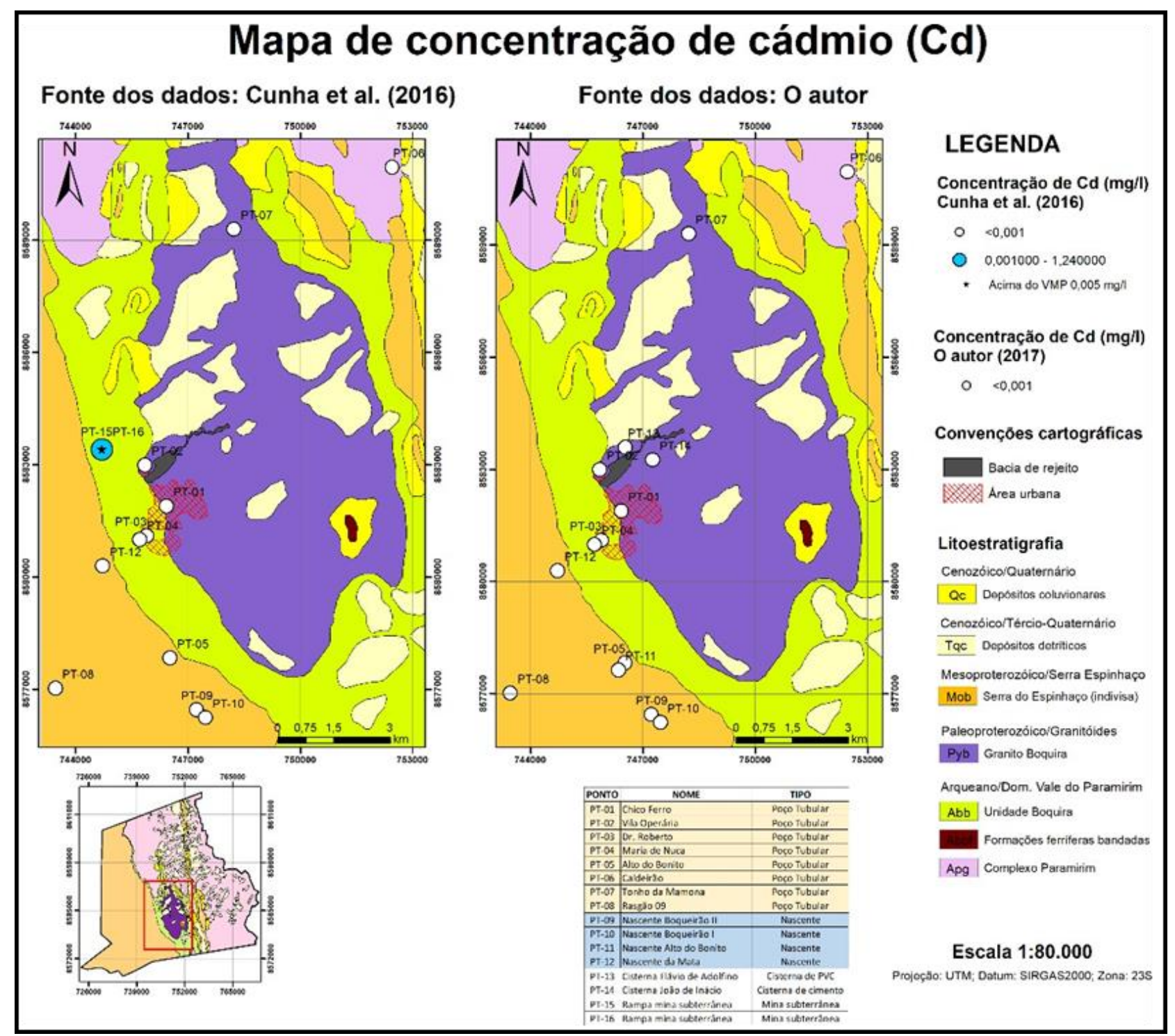

Figura 6 - Concentração de cádmio (Cd) nos pontos amostrados por Cunha et al. (2016) e o autor (2016) (Adaptado de Arcanjo et al., 2000; Cunha et al., 2016).

setembro/2016, encontrou para os pontos PT-01 (134 mg/L), PT-02 (146 mg/L) e PT-03 (119 $\mathrm{mg} / \mathrm{L}$ ) (Figura 7) valores inferiores aos encontrados por Cunha et al. (2016), porém ainda acima do VMP definido por WHO (2011).
O ferro é um dos metais mais abundante na crosta terrestre, sendo comumente encontrado em fontes de água de consumo humano em níveis variando entre $0,5 \mathrm{mg} / \mathrm{L}$ a $50 \mathrm{mg} / \mathrm{L}$. A origem natural desse ferro está ligada a processos 
de lixiviação do solo, dissolução de minerais como olivinas, piroxênios e anfibólios e bactérias aeróbicas conhecidas como ferro-bactérias. De acordo com a Resolução CONAMA $n^{\circ}$ 396/2008 e a Portaria MS n ${ }^{\circ}$ 2914/2011 o valor máximo permitido de $\mathrm{Fe}$ em água para o consumo humano é de $0,3 \mathrm{mg} / \mathrm{L}$.

Os resultados obtidos durante a campanha II (setembro/2016), espacializados na figura 8, mostram que os valores encontrados variam de $<0,01$ a $0,538 \mathrm{mg} / \mathrm{L}$. Dos quatorze pontos analisados nesta campanha, somente o PT-11 (Nascente Alto do Bonito) apresentou resultado acima do VMP, com o valor de $0,538 \mathrm{mg} / \mathrm{L}$. Os resultados obtidos por Cunha et al. (2016), espacializados na figura 8 , mostram valores que variam entre 0,015 a 82,6 mg/L. Os pontos PT-06
(Caldeirão) e PT-10 (Nascente Boqueirão I) apresentaram resultados acima dos VMP, com $82,6 \mathrm{mg} / \mathrm{L}$ e $0,330 \mathrm{mg} / \mathrm{L}$, respectivamente.

Ao comparar os resultados do ponto PT-06 (Caldeirão) observa-se significativa divergência entre os valores obtidos na campanha II de amostragem (setembro/2016) e por Cunha et al. (2016) em julho/2013, apresentando valores $82,6 \mathrm{mg} / \mathrm{L}$ (Cunha et al., 2016) e $0,01 \mathrm{mg} / \mathrm{L}$ na campanha II. O PT-06 está situado sob domínio geológico do Complexo Paramirim, composto basicamente por gnaisses bandados portadores de feições de anatexia, biotita ortognaisses tonalítico-granodioríticos migmatíticos, biotita ortognaisses tonalíticos a graníticos e gnaisses migmatíticos (Arcanjo et al., 2000).

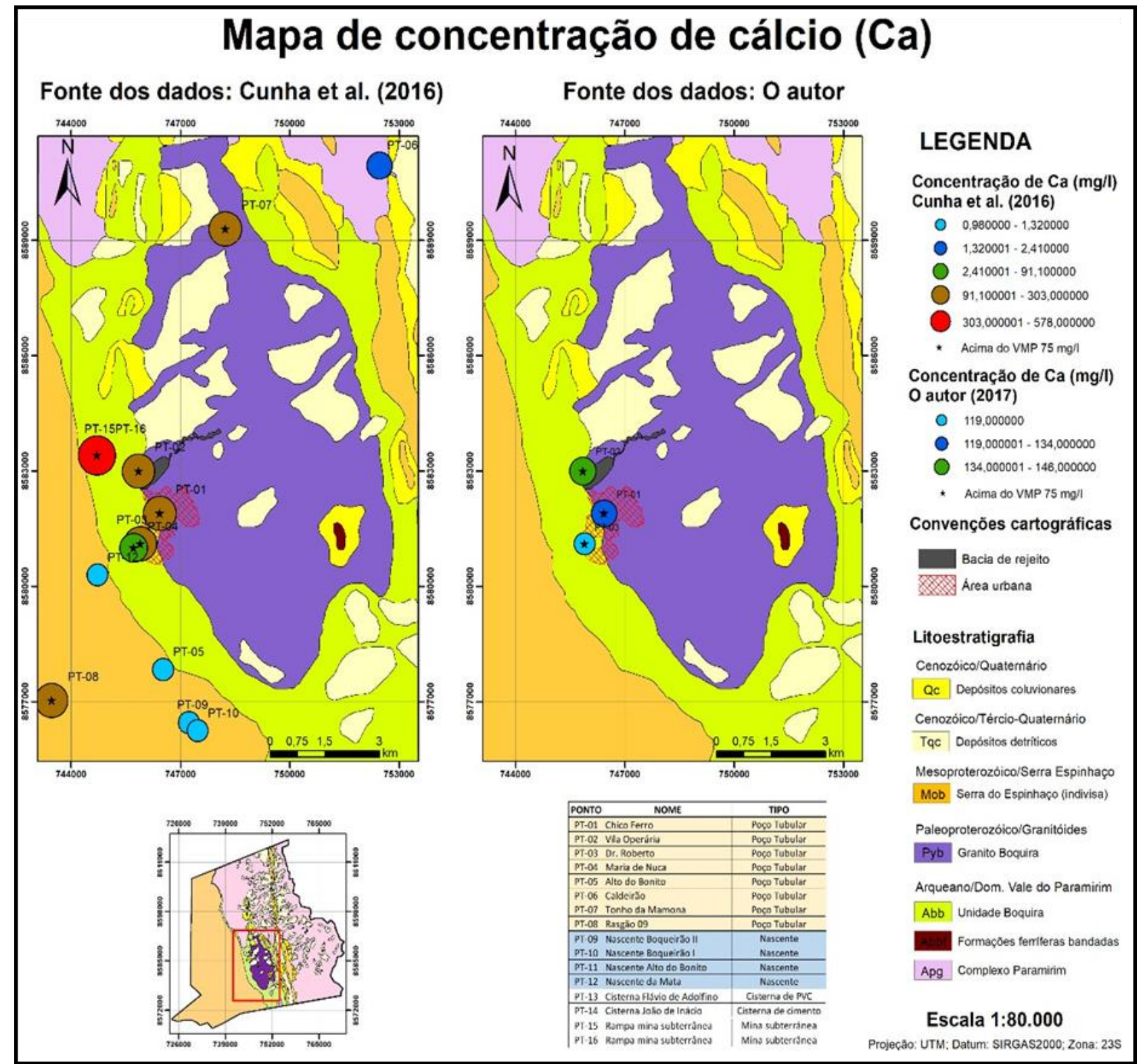

Figura 7 - Concentração de cálcio (Ca) nos pontos amostrados por Cunha et al. (2016) e o autor (2016). (Adaptado de Arcanjo et al., 2000; Cunha et al., 2016). 
A litologia da área em questão não se apresenta compatível com valores elevados para Fe, optandose então, frente à divergência encontrada nos dois dados, por erro analítico, contaminação ou devido ao fato da amostragem de Cunha et al. (2016) ter sido realizada em período de longa estiagem, utilizar então o valor da campanha II (setembro/2016) para Fe no PT-06 de <0,01 mg/L.

$\mathrm{O}$ magnésio em fonte de águas naturais ocorre proveniente da dissolução de rochas carbonáticas ricas em minerais como magnesita e dolomita (WHO, 2011). Os resultados das análises para magnésio (Figura 9) obtidos por Cunha et al. (2016) em campanha realizada em julho/2013 apresentaram valores entre $0,53 \mathrm{mg} / \mathrm{L}$ e 139 $\mathrm{mg} / \mathrm{L}$ para poços tubulares e nascentes, sendo para PT-01: 96 mg/L; PT-02: 139 mg/L; PT-03: $113 \mathrm{mg} / \mathrm{L} ;$ PT-07: $100 \mathrm{mg} / \mathrm{L}$. Os resultados obtidos nas análises da campanha II (setembro/2016) para os pontos PT-01, PT-02 e PT-03 apresentaram valores de $38,7 \mathrm{mg} / \mathrm{L}, 60 \mathrm{mg} / \mathrm{L}$ e $40,1 \mathrm{mg} / \mathrm{L}$, respectivamente. De acordo com o VMP utilizado por WHO (2011) de $50 \mathrm{mg} / \mathrm{L}$, os pontos descritos acima encontram-se acima do VMP para os valores encontrados em campanha realizada em julho/2013 por Cunha et al. (2016), enquanto que na campanha II, realizada em setembro/2016, somente o ponto PT-02 se manteve acima do VMP. Os resultados encontrados nas análises dos pontos PT-15 e PT-16 (rampa da mina subterrânea), amostrados na campanha de 2013 por Cunha et al. (2016), apontam valores 7,8 vezes acima do VMP por WHO (2011) de $50 \mathrm{mg} / \mathrm{L}$.

\section{Mapa de concentração de ferro (Fe)}

Fonte dos dados: Cunha et al. (2016)

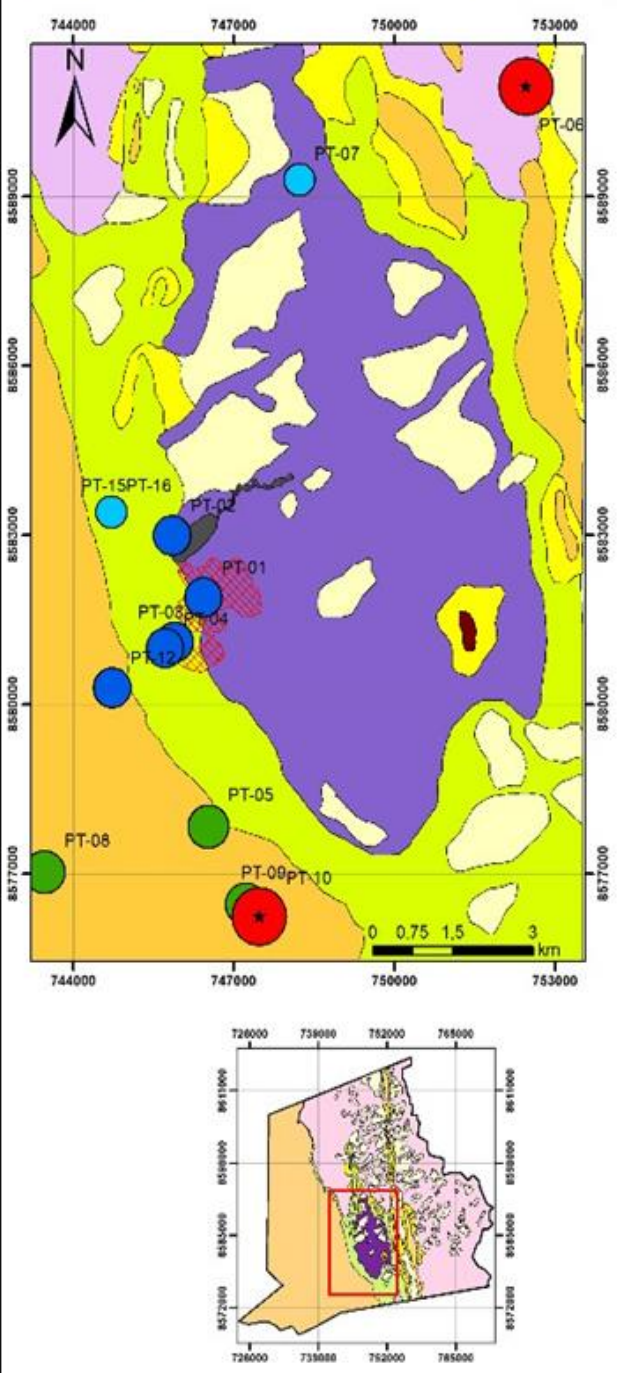

Fonte dos dados: $\mathrm{O}$ autor

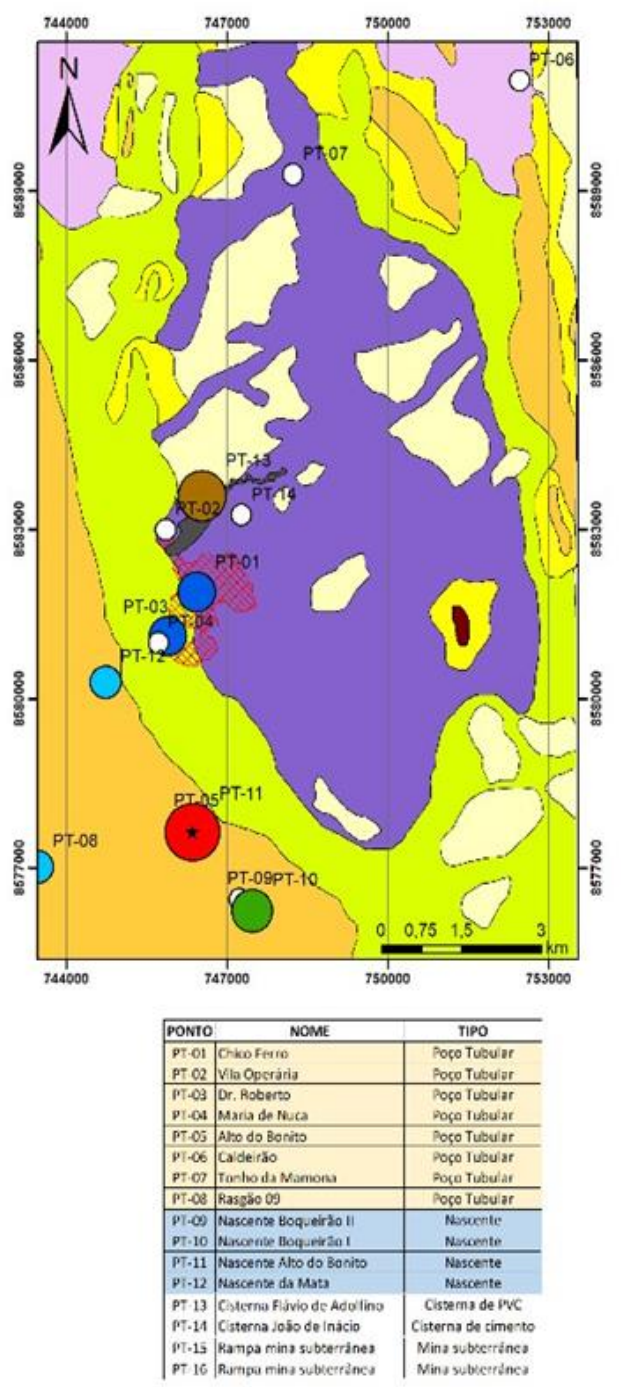

\section{LEGENDA}

Concentração de $\mathrm{Fe}(\mathrm{mg} / \mathrm{l})$ Cunha et al. (2016)

- $0.015000-0,050000$

$0.050001-0.202000$

$0,202001-0.245000$

$0.245001-0.320000$

$0,320001-82,600000$

* Acima do VMP 0,3 mgil

Concentraçăo de $\mathrm{Fe}(\mathrm{mg} / \mathrm{l})$

O autor (2017)

o $<0,01$

O $0.010000-0.011200$

$0.011201 \cdot 0.013200$

$0.013201-0.018100$

$0.018101-0.029300$

$0.029301-0,538000$

* Acima do VMP $0,3 \mathrm{mg}$

Convençőes cartográficas

Bacia de rejeito

Area urbana

Litoestratigrafia

Cenozóico/Quaternário

Qc Depositos colluvionares

Cenozóico/Tércio-Quatemário

Tqc Dopositos dotriticos

Mesoproterozóico/Serra Espinhaço

Mob Serra do Espinhaço (indivisa)

Paleoproterozóico/Granitóides

Pyb Granito Boquire

Arqueano/Dom. Vale do Paramirim

Abb Unidade Boquira

Formaçoes ferrileras bandadas

Apg Complexo Paraminim

Escala 1:80.000

Proję̧ిo: UTM: Datum: SIRGAS2000: Zona: 235

Figura 8 - Concentração de ferro (Fe) com base nos valores obtidos por Cunha et al. (2016) (mapa à esquerda) e campanha II (mapa à direita) (Adaptado de Arcanjo et al., 2000; Cunha et al., 2016). 


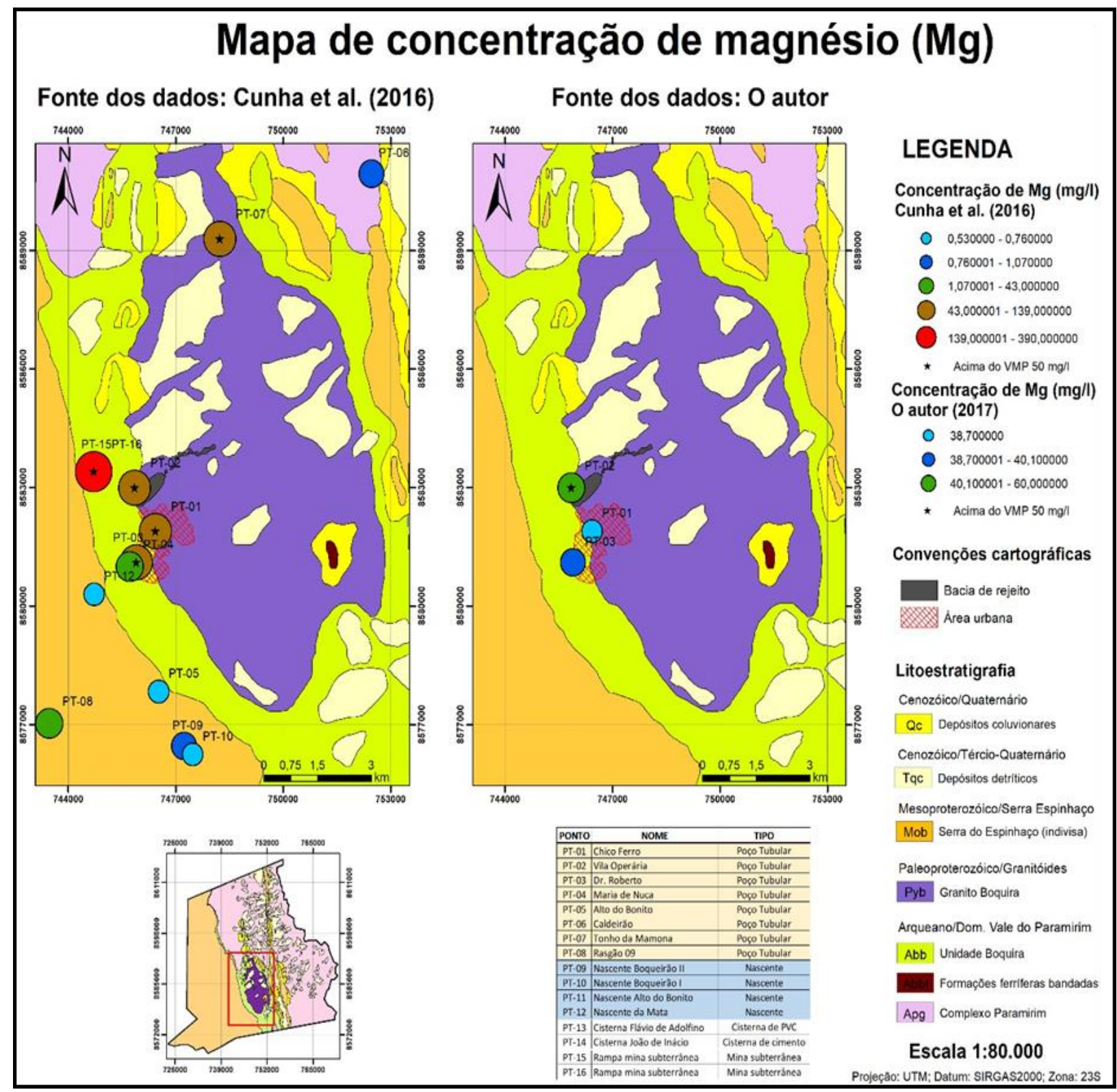

Figura 9 - Concentração de magnésio (Mg) com base nos valores obtidos por Cunha et al. (2016) (mapa à esquerda) e campanha II (mapa à direita) (Adaptado de Arcanjo et al., 2000; Cunha et al., 2016).

Para Mendes \& Oliveira (2004), a ocorrência de sais de sódio é usual em rochas com mineralogia abundante em plagioclásio, micas, anfibólio e piroxênios, assim como em águas residuais domésticas, devido às excreções humanas.Para Santos (2008) a ocorrência de sódio em larga escala nas águas naturais se dá devido ao elevado número de minerais que contém sódio na composição e a baixa estabilidade química destes e altas taxas de solubilidade.

De acordo com a Resolução CONAMA ${ }^{\circ}$ $396 / 2008$ e a Portaria MS $n^{\circ}$ 2914/2011, o valor máximo permitido de concentração para sódio em água para o consumo humano é de $200 \mathrm{mg} / \mathrm{L}$.

A campanha de amostragem realizada por Cunha et al. (2016), em julho/2013, apresentou resultados superiores ao VMP para os pontos PT-
01 (310 mg/L) e PT-02 (234 mg/L) (Figura 10).

Os valores obtidos para os pontos PT-01 e PT02 na campanha de setembro/2016 apresentaram valores de $153 \mathrm{mg} / \mathrm{L}$ e $134 \mathrm{mg} / \mathrm{L}$ (figura 10), respectivamente.

Apesar da diferença entre os valores obtidos por Cunha et al. (2016) cujos valores para os pontos PT-01 e PT-02 estão acima do VMP e na campanha II (setembro/2016) cujos valores para os pontos PT-01 e PT-02 estão abaixo do VMP, observa-se que os valores mesmo abaixo do VMP são elevados (assim como nos pontos PT-03 e PT-04) em relação aos demais pontos.

$\mathrm{O}$ nitrato tem ocorrência natural nas águas subterrâneas, porém a presença em concentrações elevadas, em especial nas fontes de água potável, tem se tornado um problema cada vez mais recorrente em nível mundial. 


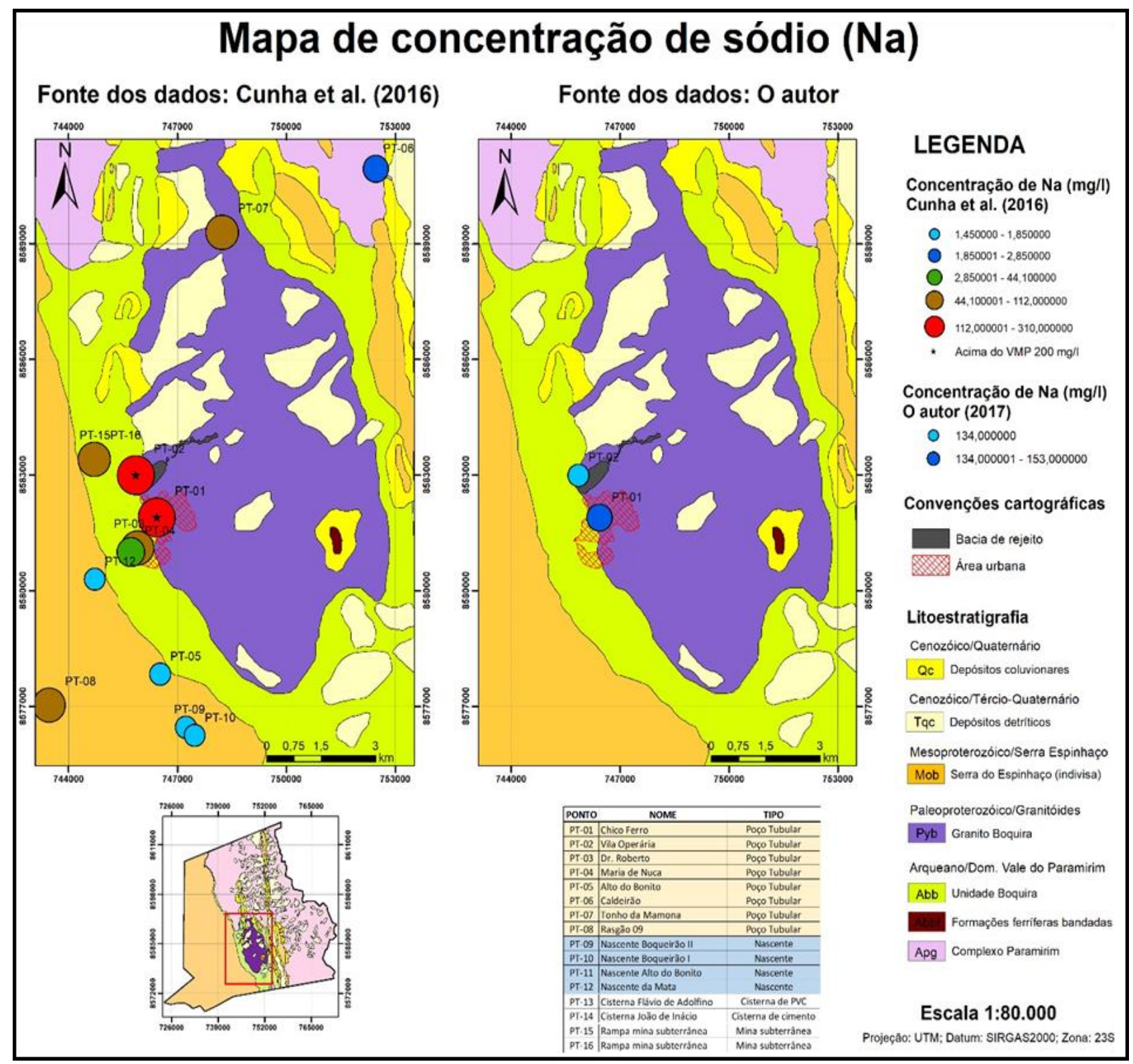

Figura 10 - Concentração de sódio $(\mathrm{Na})$ com base nos valores obtidos por Cunha et al. (2016) (mapa à esquerda) e campanha II (mapa à direita) (Adaptado de Arcanjo et al., 2000; Cunha et al., 2016).

A origem do nitrato elevado em águas subterrâneas dá-se principalmente a partir de quatro fontes:

I) aplicação de fertilizantes ricos em nitrogênio e fertilizantes inorgânicos; II) matéria orgânica em quantidades excessivas no ambiente; III) saneamento básico deficiente, em especial sistemas como fossas sépticas, que comumente permitem a passagem de contaminantes para o meio e; IV) resíduos sólidos depositados de maneira inadequada (WHO, 2011).

Das 14 amostras analisadas para nitrato na campanha II (Figura 11), seis delas (PT-01, PT02, PT-03, PT-04, PT-07 e PT-14) apresentaram valores maiores que $10 \mathrm{mg} / \mathrm{L}$, que é o valor máximo permitido para consumo humano de acordo com a Resolução CONAMA $n^{\circ} 396 / 2008$ e Portaria MS n ${ }^{\circ}$ 2914/2011, sendo este valor também utilizado pela Agência de Proteção Ambiental dos Estados Unidos. Os pontos de amostragem de água subterrânea PT-01 (117,45 mg/L), PT-02 $(55,94 \mathrm{mg} / \mathrm{L})$, PT-03 (67,83 mg/L), PT-04 $(12,73 \mathrm{mg} / \mathrm{L})$, situados na zona urbana e PT- 07 $(42,71 \mathrm{mg} / \mathrm{L})$, situado na zona rural, apresentam como prováveis fontes de contaminação o mal funcionamento do sistema de fossas sépticas utilizados em grande parte das residências do município.

Segundo a Prefeitura Municipal de Boquira, até o ano de 2014 o município de Boquira possuía somente $28 \%$ da cidade com esgotamento sanitário adequado. É possível 
associar também a contaminação ao uso de fertilizantes nas pequenas agriculturas e contaminantes de origem animal (fezes). Os PT-01 e PT-02, estão ainda situados em cotas altimétricas inferiores às da bacia de rejeito, na qual está instalada há mais de 10 anos o depósito de resíduos domésticos (lixão) do município de Boquira, sendo este um potencial agente de contaminação por nitrato.

O ponto de amostragem PT-14 (10,51 mg/L) corresponde a uma cisterna de cimento com captação da água da chuva através do telhado da residência. Apesar da orientação dada a população de evitar a captação da primeira chuva com o objetivo de limpeza e remoção de particulados acumulados no telhado, devido à escassez de chuva, muitos habitantes que utilizam esse sistema não seguem esta orientação, captando junto com a água da chuva, diversos contaminantes como fezes de animais.

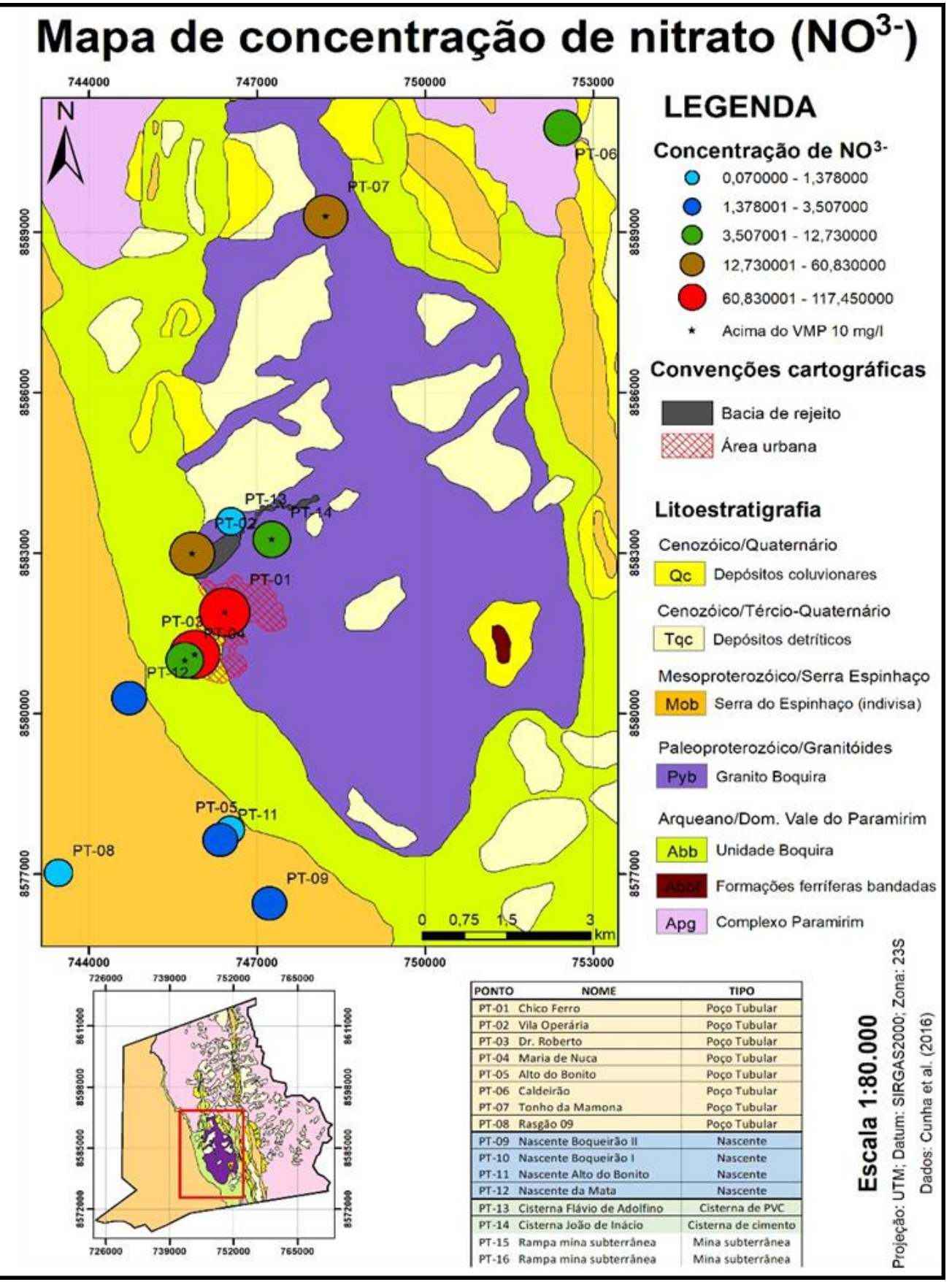

Figura 11 - Concentração de nitrato $\left(\mathrm{NO}_{3}{ }^{-}\right)$com base nos valores obtidos na campanha II (Adaptado de Arcanjo et al., 2000).

\section{CONSIDERAÇÕES FINAIS}

Concluiu-se que existe a influência do background natural das rochas do município de Boquira nos recursos hídricos utilizados pela população, conferido valores acima do Valor Máximo Permitido para consumo humano para metais como cálcio, ferro, magnésio e sódio. 
Apesar das maiores concentrações para metais como chumbo, zinco e cádmio estarem situadas nas águas das galerias da mina subterrânea e bacia de rejeito, não foi encontrado elevados teores desses metais nos recursos hídricos para abastecimento humano (poço tubular, nascente $\mathrm{e}$ cisternas abastecidas por água da chuva) no município de Boquira.

\section{REFERÊNCIAS}

ARCANJO, B.A.; VARELA, P.H.L.; MARTINS, A.A.M.; LOUREIRO, H.S.C.; NEVES, J.P. Projeto Vale do Paramirim: Estado da Bahia. Programa Levantamentos Geológicos Básicos do Brasil - PLGB. Convênio CBPM/CPRM. Relatório Interno. 105 p., 2000.

BERTOLINO, L.C.; ALVES, F.E.A.; MENDES, J.C.; NEUMANN, R. Caracterização mineralógica preliminar de amostras do rejeito da antiga mineração de chumbo em Boquira, Bahia. Comunicações Geológicas, v. 101, p. 965 968, 2014.

BRASIL - CONSELHO NACIONAL DO MEIO AMBIENTE. Resolução 357, de 17 de março de 2005. Dispõe sobre a classificação dos corpos de água e diretrizes ambientais para o seu enquadramento, bem como estabelece as condições e padrões de lançamento de efluentes, e dá outras providências. Disp. em: http://www.mma.gov.br/port/conama/pdf. Acessado em: 05jul2015.

BRASIL - CONSELHO NACIONAL DO MEIO AMBIENTE. Resolução 396, de 03 de abril de 2008. Dispõe sobre a classificação e diretrizes ambientais para o enquadramento das águas subterrâneas e dá outras providências. Disp. em: http://www.mma.gov.br/port/conama/pdf. Acessado em: 05 jul2015.

BRASIL - MINISTÉRIO DA SAÚDE. Portaria n 2914/2011, de 12 de dezembro de 2011. Dispõe sobre os procedimentos de controle e de vigilância da qualidade da água para consumo humano e seu padrão de potabilidade. Disponível em: http://www.comitepcj.sp.gov.br/Portaria_MS_2914-11.pdf. Acessado em: 05jul2015.

BUSINELLI, D.; MASSACCESI, L.; ONOFRI, A. Evaluation of $\mathrm{Pb}$ and $\mathrm{Ni}$ mobility to groundwater in calcareous urban soils of Ancona, Italy. Water Air Soil Pollut. v. 201, n. 1, p, 185-193, 2009.

CORNEJO, C.C. \& BARTORELLI, A. Minerais e pedras preciosas do Brasil. São Paulo: Solaris edições culturais, 704 p., 2010.

CUNHA, F.G.; VIGLIO, E.P.; ANJOS, J.A.S.A.; LOUREIRO, T.B. Estudos geoquímicos no município de Boquira - Estado da Bahia. CPRM: 37 p., 2016.

ESPOURTEILLE, F. \& FLEISCHER, R. A mina de Boquira. In: INDA, H.A.V.; DUARTE, F.B., Geologia e Recursos Minerais do Estado da Bahia: textos básicos. Salvador: SME, v. 3, p. 104-125, 1980

GARCIA, P.M.P. Análise comparativa de dados geológicos, litogeoquímicos e geofísicos das formações ferríferas do complexo Boquira e supergrupo Espinhaço na região de
Boquira, BA. Salvador, 2011. 165 p. Monografia (Graduação em Geologia) - Instituto de Geociências, Universidade Federal da Bahia.

GIAMPA, C.E.Q. \& GONÇALES, V.G. Águas Subterrâneas e poços tubulares profundos. São Paulo: Oficina de Textos, 498 p., 2013.

INSTITUTO BRASILEIRO DE GEOGRAFIA E ESTATÍSTICA - IBGE. Cidades. 2015. Disp. em: http://cidades.ibge.gov.br. Acessado em: 11 nov2015.

LIMA, A. Composição e Origem das Águas Minerais Naturais: Exemplo de Caldas da Saúde. Lisboa: Edições Almedina, 246 p., 2010.

LIMA, O.A.L. Geosistemas e recursos hídricos: água subterrânea no estado da Bahia. SEI. Bahia análise \& dados. v. 13, p. 391402, 2003

LOGAN, J. Interpretação de análises químicas de água. Recife: Agency for International Development, 67 p., 1965.

MENDES, B. \& OLIVEIRA, J.F.S. Qualidade da Água para Consumo Humano. Lisboa: Lidel, Edições Técnicas Ltda., 626 p, 2004.

PAOLIELLO, M.M.B. \& CAPITANI, E.D. Chumbo. In: AZEVEDO, F.A.; CHASIN, A.A.M. METAIS: GERENCIAMENTO DE TOXICIDADE. São Paulo: Ed. Atheneu, p. 353-398, 2003.

ROCHA, G.M.F. Caracterização faciológica da formação ferrífera de Boquira, encaixante da mineralização de Pb/Zn. Salvador, 1985, 120 p. Dissertação (Mestrado em Geologia) - Instituto de Geociências, Universidade Federal da Bahia.

SANTOS, A.C. Noções de hidroquímica. In: FEITOSA A.C.; MANOEL FILHO, J.; FEITOSA, E.C.; DEMETRIO, J.G.A. (Organizadores). Hidrogeologia: conceitos e aplicações. Fortaleza: CPRM, LABHID-UFPE, p. 81-108, 2008.

WHO. World Health Organization. Guidelines for drinkingwater Quality. Estados Unidos da América, 564 p., 2011.

Submetido em 30 de março de 2019 Aceito em 6 de dezembro 2019 